\title{
The effects of sevoflurane and propofol anesthesia on cerebral oxygenation in gynecological laparoscopic surgery
}

\author{
Sung-Jin Kim, Jae Young Kwon, Ah-Reum Cho, Hae Kyu Kim, and Tae Kyun Kim \\ Department of Anesthesia and Pain Medicine, Pusan National University Hospital, Busan, Korea
}

Background: Both the Trendelenburg position and pneumoperitoneum with carbon dioxide have been reported to increase intracranial pressure (ICP) and to alter cerebral blood flow or cerebral blood volume. Also anesthetic agents have variable effects on cerebral hemodynamics and ICP. The present study was conducted to determine whether regional cerebral oxygen saturation $\left(\mathrm{rSO}_{2}\right)$ values differ between propofol and sevoflurane anesthesia during laparoscopic surgery in the Trendelenburg position.

Methods: Thirty-two adult women undergoing gynecological laparoscopic surgery were divided into sevoflurane and propofol groups. $\mathrm{rSO}_{2}$ values were recorded at $10 \mathrm{~min}$ after induction in the neutral position (Tpre), $10 \mathrm{~min}$ after the pneumoperitoneum in the Trendelenburg position (Tpt) and $10 \mathrm{~min}$ after desufflation in the neutral position (Tpost). For analysis of $\mathrm{rSO}_{2}$, we did ANOVA and univariate two-way ANCOVA with covariates being mean arterial pressure and end tidal carbon dioxide tension.

Results: Between sevoflurane and propofol groups, the change in $\mathrm{rSO}_{2}$ was significantly different even after ANCOVA. $\mathrm{rSO}_{2}$ at Tpt (76.3 $\pm 5.9 \%$ in sevoflurane vs $69.4 \pm 5.8 \%$ in propofol $)$ and Tpost $(69.5 \pm 7.1 \%$ in sevoflurane vs $63.8 \pm 6.6 \%$ in propofol) were significantly higher in the sevoflurane group compared with the propofol group. In the propofol group, $\mathrm{rSO}_{2}$ at Tpost was significantly lower than at Tpre $(71.1 \pm 4.8 \%)$ and cerebral oxygen desaturation occurred in two patients (14.3\%).

Conclusions: Significantly lower $\mathrm{rSO}_{2}$ values were observed in the propofol group during gynecological laparoscopic surgery. The possibility of cerebral oxygen desaturation should not be overlooked during propofol anesthesia even after desufflation of the abdomen in the neutral position. (Korean J Anesthesiol 2011; 61: 225-232)

Key Words: Cerebral hypoxia, Head-down tilt, Near-infrared spectroscopy, Pneumoperitoneum, Propofol, Sevoflurane.

\footnotetext{
Received: March 7, 2011. Revised: March 28, 2011. Accepted: April 5, 2011.

Corresponding author: Jae Young Kwon, M.D., Department of Anesthesia and Pain Medicine, Pusan National University Hospital, 305, Gudeokro, Seo-gu, Busan 602-739, Korea. Tel: 82-51-240-7399, Fax: 82-51-242-7466, E-mail: jykwon@pusan.ac.kr

(c) This is an open-access article distributed under the terms of the Creative Commons Attribution Non-Commercial License (http:// creativecommons.org/licenses/by-nc/3.0/), which permits unrestricted non-commercial use, distribution, and reproduction in any medium, provided the original work is properly cited.
} 


\section{Introduction}

Laparoscopic surgery has greatly developed recently and is becoming a standard surgical procedure because of its important advantages, namely less tissue trauma, decreased postoperative pain, as well as a shorter hospital stay with minimized postoperative morbidity and mortality. In gynecologic surgery, laparoscopic operations usually require a steep Trendelenburg position and artificial pneumoperitoneum with carbon dioxide $\left(\mathrm{CO}_{2}\right)$ insufflation. In the steep Trendelenburg position, intracranial pressure (ICP) increases due to increased venous pressure, which hinders cerebral venous drainage with a consequential increase in the cerebral blood volume (CBV) and cerebrospinal fluid (CSF) volume [1,2]. The pneumoperitoneum with $\mathrm{CO}_{2}$ also elevates ICP because increased abdominal pressure obstructs venous return from the lumbar venous plexus [3], and increased cerebral blood flow (CBF) due to an increase in arterial partial pressure of carbon dioxide $\left(\mathrm{PaCO}_{2}\right)$ and catecholamine release independent of $\mathrm{PaCO}_{2}$ [4].

Near-infrared spectroscopy (NIRS) cerebral oximetry allows continuous and noninvasive monitoring of regional cerebral oxygen saturation $\left(\mathrm{rSO}_{2}\right)$. Cerebral oxygen saturation reflects the balance between cerebral oxygen supply and demand and it is affected by changes in blood oxygenation, $\mathrm{CBF}$, hemoglobin $(\mathrm{Hb})$ content, and cerebral metabolic rate of oxygen $\left(\mathrm{CMRO}_{2}\right)$ [5]. A number of clinical studies and case reports have demonstrated the ability of cerebral oximetry monitoring to detect changes in $\mathrm{CBF}$ and cerebral ischemia [68]. In a recent study in patients with subarachnoid hemorrhage, episodes of angiographic cerebral vasospasm were strongly associated with a reduction in the ipsilateral NIRS signal [6]. NIRS can be a valuable tool for detection of cerebral ischemia during carotid endarterectomy (CEA) [7]. Furthermore, a significant correlation between $\mathrm{rSO}_{2}$ values immediately after declamping and changes in CBF was found, and can be used for detecting patients at risk of developing post-CEA hyperperfusion syndrome [8]. The use of NIRS in laparoscopic surgery in the Trendelenburg position has been studied, but results have been equivocal. Lee et al. [9] reported that $\mathrm{rSO}_{2}$ declined significantly in the Trendelenburg position during gynecological laparoscopic surgery under isoflurane anesthesia. They reported that it was caused by a reduction in cerebral perfusion pressure (CPP) as a result of an increase in ICP, CBF, and CBV. In contrast, some studies $[10,11]$ demonstrated that with inhaled anesthetics $\mathrm{rSO}_{2}$ was increased during abdominal surgery in the Trendelenburg position and this was, ironically, explained by increased CBF and CBV.

It is well known that anesthetic agents have variable effects on cerebral hemodynamics and ICP. Consequently, the choice of maintenance anesthetic could be important in laparos- copic surgery in order to minimize adverse cerebrovascular responses. Inhaled anesthetics have a dual effect on the cerebral vasculature. In low concentrations halothane, isoflurane, and sevoflurane constrict cerebral vessels secondary to suppression of $\mathrm{CMRO}_{2}$. With increasing concentration, the direct vasodilatory effect of inhaled anesthetics turns dominant, leading to high CBF and CBV and to elevated ICP. However, propofol reduces $\mathrm{CMRO}_{2}, \mathrm{CBF}, \mathrm{CBV}$, and ICP in a dosedependent manner [12]. Several studies have demonstrated that the reduction in CBF is larger than the reduction in $\mathrm{CMRO}_{2}$, which suggests that propofol may have direct cerebral vasoconstricting activity [13], which might lead to a decrease in cerebral perfusion and a decrease in the $\mathrm{CBF} / \mathrm{CMRO}_{2}$ ratio. In situations where there is an increased ICP, such as a brain tumor, inhaled anesthetics had a significantly higher $\mathrm{CBF} / \mathrm{CMRO}_{2}$ ratio or jugular venous oxygen saturation $\left(\mathrm{SjO}_{2}\right)$ compared with propofol [14-16]. Since laparoscopic surgery in the Trendelenburg position also elevates CBF, CBV and ICP, we hypothesized that, during sevoflurane anesthesia, $\mathrm{rSO}_{2}$ is more favorable compared with propofol anesthesia during laparoscopic surgery in the Trendelenburg position.

\section{Materials and Methods}

\section{Patient selection}

The study was performed on patients who were undergoing gynecological laparoscopic surgery under general anesthesia. Thirty two adult women between 18 and 60 years old with an American Society of Anesthesiologists physical status of I or II were enrolled. Exclusion criteria were as follows: a history of any cerebrovascular disease, poorly controlled hypertension, or obesity (body mass index $>30$ ). Ethical approval for the study was given by the Institutional Review Board of our Hospital and all patients were given written informed consent before enrollment.

\section{Study protocol}

In this study, two groups were identified according to the method of general anesthesia, one with sevoflurane and remifentanil, and the other with total intravenous anesthesia using target controlled infusion (TCI) of propofol and remifentanil. Randomization was done by two independent anesthesiologists using 32 opaque sealed envelopes, 16 for each group, indicating patient group assignment and describing the anesthetic protocol. The patients and anesthesiologists involved in data collection and analysis of results, were not aware of group assignments.

All patients received $3 \mathrm{mg}$ of midazolam and $0.2 \mathrm{mg}$ of 
glycopyrrolate intramuscularly 30 min before surgery. Standard monitoring and bispectral index (BIS; Bispectral Index ${ }^{\mathrm{TM}}$, Aspect Modical System Inc., Norwood, MA, USA) monitoring were done. Before induction of anesthesia, a $20 \mathrm{G}$ radial artery catheter was inserted for continuous arterial pressure monitoring and arterial blood gas analysis. For $\mathrm{rSO}_{2}$ measurement, sensors for cerebral oximetry were placed bilaterally above the eyebrow on the right and left sides of the forehead before induction of anesthesia. The $\mathrm{rSO}_{2}$ value was continuously monitored using NIRS (INVOS 5100; Somanetics Corp., Troy, Michigan, USA). The values for each side were averaged.

In the sevoflurane group, general anesthesia was induced with $1.5 \mathrm{mg} / \mathrm{kg}$ of propofol, $8 \mathrm{vol} \%$ of sevoflurane and continuous remifentanil infusion using TCI (Orchestra ${ }^{\circledR}$ with Base Primea, Fresenius Kabi, France) to reach 2 ng/ml for the target effect site concentration. In the propofol group, anesthesia was induced with continuous propofol and remifentanil infusion by TCI to reach $4 \mu \mathrm{g} / \mathrm{ml}$ and $2 \mathrm{ng} / \mathrm{ml}$ of target effect site concentration, respectively. Once the BIS was stable between 40 and $50,0.8 \mathrm{mg} / \mathrm{kg}$ of rocuronium was used to facilitate tracheal intubation. Anesthesia was maintained by a mixture of oxygen and air with a fixed $\mathrm{FiO}_{2}$ of 0.5 , and mechanical ventilation was adjusted to maintain an end tidal $\mathrm{CO}_{2}$ tension $\left(\mathrm{ETCO}_{2}\right)$ of 30 to $35 \mathrm{mmHg}$ throughout the surgery.

The BIS was used to guide administration of sevoflurane and propofol. The BIS target range during maintenance was 40 to 50. Clinical signs of inadequate anesthesia were treated with increasing or decreasing the inspired concentration of sevoflurane or the target effect site concentration of propofol. Mean arterial pressure (MAP) and heart rate (HR) were used to guide the administration of remifentanil. Both variables were maintained within $20 \%$ of baseline, if hypotension (MAP $<60$ $\mathrm{mmHg}$ ) or bradycardia (HR $<45$ beats $/ \mathrm{min}$ ) persisted more than $5 \mathrm{~min}$, the patient was treated with ephedrine $10 \mathrm{mg}$ or atropine $0.5 \mathrm{mg}$. A case was excluded if the patient was given ephedrine or atropine more than three times.

After induction of general anesthesia, patients were positioned in the low lithotomy position and the abdominal cavity was insufflated with $\mathrm{CO}_{2}$ gas pressure set to $15 \mathrm{mmHg}$. Patients were then placed in the Trendelenburg position of $20^{\circ}$ during surgery. MAP, $\mathrm{HR}$, oxygen saturation $\left(\mathrm{SpO}_{2}\right), \mathrm{rSO}_{2}, \mathrm{ETCO}_{2}$, endtidal sevoflurane tension (ETsevo), effect site concentration of propofol, esophageal temperature, $\mathrm{Hb}$, arterial oxygen partial pressure $\left(\mathrm{PaO}_{2}\right)$, and arterial $\mathrm{CO}_{2}$ partial pressure $\left(\mathrm{PaCO}_{2}\right)$ were recorded at $10 \mathrm{~min}$ after induction in the neutral position (Tpre), 10 min after the insufflation of the abdomen with $\mathrm{CO}_{2}$ in the Trendelenburg position (Tpt) and $10 \mathrm{~min}$ after desufflation of the abdomen in the neutral position (Tpost).

Any complications, including nausea, vomiting, headache, blurred vision, or neurologic deficits were recorded in the recovery room $60 \mathrm{~min}$ after the operation. Duration of anesthesia, operation, and Pneumoperitoneum-Trendelenburg time (P-T time), total dose of remifentanil given in the operating room, blood loss, urine output, and IV fluid volume were also recorded.

Cerebral oxygen desaturation was defined as an $\mathrm{rSO}_{2}$ value $<75 \%$ of the baseline value, or an $\mathrm{rSO}_{2}$ value $<50 \%$. In the event of such a decrease in $\mathrm{rSO}_{2}$, the following algorithm was followed: normotension was ensured; the patient's neck was checked for changes in position or the presence of external factors that may have caused arterial or venous obstruction. If the decrease in $\mathrm{rSO}_{2}$ was refractory to all the above measures, $100 \%$ oxygen was administered and no further intervention was performed.

\section{Statistical analysis}

Data are expressed as mean \pm standard deviation (SD). Demographic variables, duration of surgery and anesthesia, P-T time, the total doses of remifentanil given in the operating room, blood loss, urine output, and IV fluid volume between the groups were compared using unpaired student t-tests. Hemodynamic variables, $\mathrm{rSO}_{2}$, BIS, blood gas were analyzed using two-way ANOVA with repeated measurement (intergroup comparisons) and one-way ANOVA with repeated measurement (intragroup comparisons). For analysis of $\mathrm{rSO}_{2}$ univariate two-way analysis of covariance (ANCOVA) was done with MAP and $\mathrm{ETCO}_{2}$ as the covariates. Post hoc analysis was performed with the Bonferroni/Dunn correction. The Chi square test was used to compare the incidence of intraoperative cerebral oxygen desaturation and complications. The level of statistical significance was set at $\mathrm{P}<0.05$. To calculate sample size, we used the mean and standard deviation (SD) of the first 5 patients in each group at Tpt time point. The mean $\mathrm{rSO}_{2}$ (SD) were $78.0 \%$ (6.6) and $70.0 \%$ (7.2) in the sevoflurane and propofol groups, respectively. With a type I error of 0.05 and a type II error of 0.2 , the required sample size was 13 patients in each group. We assumed a dropout rate of $20 \%$, so 32 patients were recruited. Data were analyzed using StatView version 5.0 (SAS, Chicago, IL). Sample size was determined by "G power" (the software is available and free from the web site: http:// www.psycho.uni-duesseldorf.de/aap/projects/gpower/index. html).

\section{Results}

A total of 32 patients were enrolled. Five patients were excluded: in the sevoflurane group, the surgical method was changed to laparotomy in two patients and failure to control $\mathrm{PaCO}_{2}$ in one patient; in the propofol group, cerebral oxygen 
Table 1. Demographic Variables

\begin{tabular}{|c|c|c|c|}
\hline & $\begin{array}{l}\text { Sevoflurane } \\
\quad(\mathrm{n}=13)\end{array}$ & $\begin{array}{c}\text { Propofol } \\
(\mathrm{n}=14)\end{array}$ & $P$ value \\
\hline Age (yr) & $34.7 \pm 7.2$ & $33.6 \pm 12.9$ & 0.799 \\
\hline Weight (kg) & $56.6 \pm 10.2$ & $57.8 \pm 6.3$ & 0.721 \\
\hline Height $(\mathrm{cm})$ & $160.1 \pm 6.7$ & $161.9 \pm 4.9$ & 0.422 \\
\hline Duration of anesthesia (min) & $108.6 \pm 16.3$ & $111.9 \pm 25.2$ & 0.691 \\
\hline Duration of operation (min) & $79.8 \pm 15.4$ & $84.1 \pm 26.4$ & 0.613 \\
\hline Duration of P-T time (min) & $60.6 \pm 13.9$ & $54.3 \pm 22.1$ & 0.386 \\
\hline Total dose of remifentanil $(\mu \mathrm{g})$ & $521.3 \pm 201.8$ & $567.4 \pm 130.9$ & 0.585 \\
\hline \multicolumn{4}{|l|}{ Intake (ml) } \\
\hline Crystalloid & $838.5 \pm 150.2$ & $828.6 \pm 246.3$ & 0.902 \\
\hline \multicolumn{4}{|l|}{ Output (ml) } \\
\hline Blood loss & $73.1 \pm 43.9$ & $85.7 \pm 74.5$ & 0.600 \\
\hline Urine output & $134.6 \pm 106.8$ & $114.3 \pm 74.5$ & 0.569 \\
\hline
\end{tabular}

Data are expressed as mean \pm SD. P-T time: pneumoperitoneum and Trendelenburg time. There is no significant difference between groups.

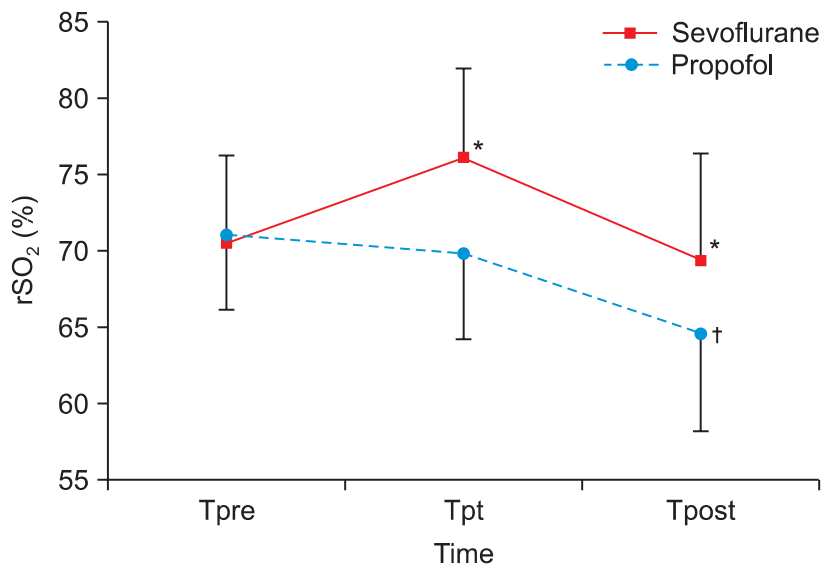

Fig. 1. Changes in regional cerebral oxygen saturation. Values are mean \pm SD, Tpre: baseline, 10 min after induction of general anesthesia in the neutral position, Tpt: $10 \mathrm{~min}$ after insufflation of the abdomen with $\mathrm{CO}_{2}$ in the Trendelenburg position, Tpost: $10 \mathrm{~min}$ after desufflation of the abdomen in the neutral position, $\mathrm{rSO}_{2}$ : regional cerebral oxygen saturation. $* \mathrm{P}<0.05$ vs propofol group, ${ }^{\dagger} \mathrm{P}<0.05$ vs Tpre with ANOVA.

desaturation occurred in two patients.

Demographic variables are shown in Table 1. There was no significant difference in demographic variables between the two groups. The change in $\mathrm{rSO}_{2}$ is shown in Fig. 1. There was a significant difference between the two groups in $\mathrm{rSO}_{2}(\mathrm{P}=0.027$ with ANOVA, $\mathrm{P}=0.021$ with ANCOVA). At Tpt, the $\mathrm{rSO}_{2}$ value was $76.3 \pm 5.9 \%$ for the sevoflurane group and $69.4 \pm 5.8 \%$ for the propofol group. At Tpost, the $\mathrm{rSO}_{2}$ value was $69.5 \pm 7.1 \%$ in the sevoflurane group and $63.8 \pm 6.6 \%$ in the propofol group. The $\mathrm{rSO}_{2}$ values at Tpt and Tpost were significantly higher in the sevoflurane group compared with the propofol group $(\mathrm{P}=0.015$ at Tpt, $\mathrm{P}=0.048$ at Tpost). In the sevoflurane group, the change in $\mathrm{rSO}_{2}$ was statistically significant by ANOVA $(\mathrm{P}=0.028)$ but was not significant with ANCOVA $(\mathrm{P}=0.957)$. Similarly, in the propofol group, the change in $\mathrm{rSO}_{2}$ was statistically significant with ANOVA $(\mathrm{P}=0.020)$ but was not significant with ANCOVA $(\mathrm{P}=0.350)$. In the sevoflurane group, $\mathrm{rSO}_{2}$ at Tpt was higher than at Tpre but the difference was not significant $(\mathrm{P}=0.028$, Bonferroni/Dunn correction). In the propofol group, $\mathrm{rSO}_{2}$ at Tpost was significantly lower than at Tpre $(\mathrm{P}=0.013)$.

There was no significant difference in hemodynamic variables, BIS values, temperature, $\mathrm{Hb}$, and blood gas analysis between the two groups (Table 2 and 3). MAP, temperature, BIS values, $\mathrm{Hb}$, and $\mathrm{PaO}_{2}$ remained constant throughout the study. However, $\mathrm{ETCO}_{2}$ was significantly higher at Tpt than at Tpre in both groups $(\mathrm{P}=0.042$ for the sevoflurane group, $\mathrm{P}=0.032$ for the propofol group). $\mathrm{PaCO}_{2}$ showed a similar pattern to $\mathrm{ETCO}_{2}$ - it was significantly higher at Tpt than at Tpre $(\mathrm{P}=0.011)$ in the sevoflurane group, whereas it was not significant in the propofol group.

The incidence of complications was significantly higher in the sevoflurane group compared with the propofol group ( $46.2 \%$ vs $7.1 \%, \mathrm{P}=0.021$ ); 6 patients complained of nausea in the sevoflurane group and 1 patient complained of headache in the propofol group. Two cases of cerebral oxygen desaturation occurred between Tpt and Tpost in the propofol group (14.3\%, $\mathrm{P}=0.157$ ), but they did not have any complications postoperatively.

\section{Discussion}

This study demonstrated that sevoflurane anesthesia provides a significantly higher $\mathrm{rSO}_{2}$ value after $\mathrm{CO}_{2}$ pneumoperitoneum and surgery in the Trendelenburg position compared with propofol anesthesia. In the sevoflurane group, $\mathrm{rSO}_{2}$ increased after the $\mathrm{CO}_{2}$ pneumoperitoneum and the Trendelenburg 
Table 2. Changes in Mean Arterial Blood Pressure, Heart Rate, Temperature, BIS, and Hemoglobin

\begin{tabular}{|c|c|c|c|c|c|}
\hline & & Tpre & Tpt & Tpost & $P$ value \\
\hline \multirow[t]{2}{*}{ MAP (mmHg) } & $\mathrm{S}$ & $76.7 \pm 8.0$ & $82.7 \pm 7.4$ & $76.8 \pm 11.5$ & 0.104 \\
\hline & $\mathrm{P}$ & $84.1 \pm 14.0$ & $87.8 \pm 12.6$ & $80.0 \pm 7.7$ & \\
\hline \multirow[t]{2}{*}{ HR (bpm) } & $\mathrm{S}$ & $83.4 \pm 8.4$ & $74.3 \pm 11.5^{*}$ & $65.2 \pm 6.4^{*}$ & 0.210 \\
\hline & $\mathrm{P}$ & $78.6 \pm 9.9$ & $70.8 \pm 11.8^{*}$ & $61.7 \pm 9.7^{*}$ & \\
\hline \multirow[t]{2}{*}{ Temperature $\left({ }^{\circ} \mathrm{C}\right)$} & $\mathrm{S}$ & $36.7 \pm 0.3$ & $36.8 \pm 0.4$ & $36.6 \pm 0.4$ & 0.464 \\
\hline & $\mathrm{P}$ & $36.4 \pm 0.3$ & $36.5 \pm 0.3$ & $36.6 \pm 0.3$ & \\
\hline \multirow[t]{2}{*}{ BIS } & $\mathrm{S}$ & $46.7 \pm 3.7$ & $44.9 \pm 5.6$ & $46.1 \pm 6.3$ & 0.920 \\
\hline & $\mathrm{P}$ & $47.6 \pm 4.7$ & $44.7 \pm 5.9$ & $48.0 \pm 5.9$ & \\
\hline \multirow{2}{*}{$\mathrm{Hb}(\mathrm{g} / \mathrm{dl})$} & $\mathrm{S}$ & $11.3 \pm 1.8$ & $11.4 \pm 1.5$ & $11.2 \pm 1.6$ & 0.739 \\
\hline & $\mathrm{P}$ & $10.9 \pm 1.1$ & $11.8 \pm 2.1$ & $10.7 \pm 1.3$ & \\
\hline
\end{tabular}

Data are expressed as mean \pm SD. Tpre: baseline, 10 min after induction of general anesthesia in the neutral position, Tpt: 10 min after insufflation of the abdomen with $\mathrm{CO}_{2}$ in the Trendelenburg position, Tpost: 10 min after desufflation of the abdomen in the neutral position, MAP: mean arterial pressure, HR: heart rate, BIS: bispectral index, Hb: hemoglobin, S: sevoflurane group, P: propofol group. *P < 0.05 vs Tpre, There is no significant difference between groups.

Table 3. Changes in Gas Analysis and Concentration of Anesthetics

\begin{tabular}{lccccc}
\hline & & Tpre & Tpt & Tpost & P value \\
\hline $\mathrm{ETCO}_{2}(\mathrm{mmHg})$ & $\mathrm{S}$ & $30.5 \pm 1.1$ & $32.8 \pm 1.1^{*}$ & $30.7 \pm 0.8$ & 0.101 \\
$\mathrm{PaCO}_{2}(\mathrm{mmHg})$ & $\mathrm{P}$ & $30.1 \pm 1.5$ & $32.0 \pm 1.2^{*}$ & $30.5 \pm 1.4$ & $35.2 \pm 2.6$ \\
$\mathrm{PaO}_{2}(\mathrm{mmHg})$ & $\mathrm{S}$ & $34.0 \pm 2.4$ & $36.5 \pm 2.7^{*}$ & $34.8 \pm 2.4$ & 0.474 \\
& $\mathrm{P}$ & $33.7 \pm 2.5$ & $35.6 \pm 2.2$ & $250.2 \pm 35.1$ & 0.756 \\
$\mathrm{ETsevo}(\mathrm{vol} \%)$ & $\mathrm{S}$ & $254.6 \pm 35.4$ & $238.8 \pm 25.4$ & $240.4 \pm 40.1$ & $1.3 \pm 0.5$ \\
Ce of propofol $(\mu \mathrm{g} / \mathrm{ml})$ & $\mathrm{P}$ & $247.6 \pm 40.4$ & $1.7 \pm 0.6$ & $3.3 \pm 0.8$ \\
\hline
\end{tabular}

Data are expressed as mean \pm SD. Tpre: baseline, 10 min after induction of general anesthesia in the neutral position, Tpt: 10 minafter insufflation of the abdomen with $\mathrm{CO}_{2}$ in the Trendelenburg position, Tpost: $10 \mathrm{~min}$ after desufflation of the abdomen in the neutral position, $\mathrm{ETCO}_{2}$ : end tidal carbon dioxide tension, $\mathrm{PaCO}_{2}$ : arterial partial pressure of carbon dioxide, $\mathrm{PaO}_{2}$ : arterial partial pressure of oxygen, ETsevo: end tidal sevoflurane tension, Ce: effect site concentration, S: sevoflurane group. P: propofol group. ${ }^{*} \mathrm{P}<0.05$ vs Tpre, There is no significant difference between groups.

position and then gradually decreased to a value close to the baseline. In the propofol group, $\mathrm{rSO}_{2}$ value did not change significantly after $\mathrm{CO}_{2}$ pneumoperitoneum and the Trendelenburg position. It decreased gradually over time, even after desufflation of the abdomen in the neutral position, and finally became significantly lower than the baseline value.

To the best of our knowledge, this is the first attempt to compare the effect of sevoflurane and propofol on cerebral oxygenation with $\mathrm{CO}_{2}$ pneumoperitoneum and the Trendelenburg position. However, it is well known that patients with an increased ICP, such as patients with a brain tumor, respond to inhaled anesthetics such as sevoflurane with a significantly higher $\mathrm{CBF} / \mathrm{CMRO}_{2}$ ratio and $\mathrm{SjO}_{2}$ compared than they do after propofol [14-16]. Mielck et al. [14] reported that 1 MAC sevoflurane reduced CBF and $\mathrm{CMRO}_{2}$ by approximately $38 \%$ and $47 \%$ respectively, compared with the awake state in cardiac patients. Vandesteene et al. [15] found that propofol at infusion rates of 6 and $12 \mathrm{mg} / \mathrm{kg} / \mathrm{h}$ decreased CBF by $28 \%$ and $39 \%$ respectively, and $\mathrm{CMRO}_{2}$ by $5 \%$ and $22 \%$, respectively.
Taken together, the $\mathrm{CBF} / \mathrm{CMRO}_{2}$ ratio can be maintained during sevoflurane based anesthesia but reduced during propofol anesthesia. $\mathrm{SjO}_{2}$ reflects the global $\mathrm{CBF} / \mathrm{CMRO}_{2}$ ratio and some studies showed results compatible with the studies we mentioned above. Muñoz et al. [16] reported that mean $\mathrm{SjO}_{2}$ values at a $\mathrm{PaCO}_{2}$ of $29 \mathrm{mmHg}$ were $56 \%$ and $50 \%$ under sevoflurane and propofol anesthesia, respectively. The incidence of "SjO $\mathrm{S}_{2}$ less than $50 \%$ " was higher under propofol anesthesia compared with sevoflurane anesthesia (60\% vs. $20 \%$ ). Their result is compatible with this study which found that there were 2 cases of cerebral oxygen desaturation in the propofol group. An imaging study also demonstrated that both anesthetic agents caused a global reduction of regional CBF, but the effect was greater for propofol than for sevoflurane [17].

Park et al. [10] and Kalmar et al. [18] reported that $\mathrm{rSO}_{2}$ increased with steep Trendelenburg positioning and pneumoperitoneum under general anesthesia with inhaled anesthetics because of increased $\mathrm{PaCO}_{2}$, MAP and catecholamine release. Their results were similar to results in this study. In each group, 
the change in $\mathrm{rSO}_{2}$ was statistically significant using one way ANOVA. But the significance disappeared when the covariates (MAP and $\mathrm{ETCO}_{2}$ ) were introduced. However, between the two groups, the change in $\mathrm{rSO}_{2}$ was significantly different even with ANCOVA. This means that propofol and sevoflurane have different effects on $\mathrm{rSO}_{2}$ in pneumoperitoneum and the Trendelenburg position independent of MAP and $\mathrm{ETCO}_{2}$.

Among factors that affect cerebral oxygenation, we could maintain blood oxygenation and $\mathrm{Hb}$ content constant by providing a fixed $\mathrm{FiO}_{2}$ and monitoring $\mathrm{PaO}_{2}$ and $\mathrm{Hb}$ with arterial blood gas analysis. We could also assume that $\mathrm{CMRO}_{2}$ was constant during the study period because BIS (between 40 and 50) was used to guide administration of sevoflurane and propofol. Alkire [19] reported that BIS correlated linearly with the magnitude of the cerebral metabolic reduction caused by propofol and isoflurane anesthesia and that it was mathematically quantifiable, and they found that sevoflurane's effect on $\mathrm{CMRO}_{2}$ is very similar to that of isoflurane. Kaisti et al. [17] also reported that sevoflurane reduced regional $\mathrm{CBF}$ less than propofol but regional $\mathrm{CMRO}_{2}$ to an extent similar to propofol at the same BIS level. In this study, $\mathrm{rSO}_{2}$ was mainly affected by CBF. The differences in CBF between sevoflurane and propofol should be taken into consideration, as suggested by the equation: $\mathrm{CBF}=\mathrm{CPP} /$ Cerebral vascular resistance $(\mathrm{CVR})$ $=(\mathrm{MAP}-\mathrm{ICP}) / \mathrm{CVR}$.

In normal subjects, the initial increases in CBV do not result in a significant elevation in ICP because there is latitude for compensatory adjustments by other intracranial compartments such as a translocation of venous blood and cerebrospinal fluid (CSF) to extracerebral vessels and the spinal CSF space, respectively. CBF velocity increases during $\mathrm{CO}_{2}$ pneumoperitoneum in response to increased $\mathrm{PaCO}_{2}$. When normocapnia is maintained, pneumoperitoneum combined with the Trendelenburg position does not induce harmful changes in intracranial dynamics [20]. However, when intracranial compliance is reduced, an increase in CBV can cause herniation or reduce CPP sufficiently to cause ischemia. Also, passive engorgement of the cerebral venous system as a result of the Trendelenburg position, compression of the jugular vein, or high intrathoracic pressure can have dramatic effects on ICP. In this study, $\mathrm{rSO}_{2}$ increased initially with $\mathrm{CO}_{2}$ pneumoperitoneum and Trendelenburg position, and gradually decreased with sevoflurane anesthesia. This can be assumed to occur for the situations we mentioned above. One is that $\mathrm{rSO}_{2}$ initially increased and returned to baseline by compensatory adjustment such as translocation of venous blood. Another is probably due to a decreased CPP as ICP and CBV increase. Kalmar et al. [18] demonstrated that CPP increased significantly after institution of the steep Trendelenburg position, and remained well above what is considered to be the lower limit for autoregulation of CBF during the whole procedure. So we can assume that the reason $\mathrm{rSO}_{2}$ initially increased and returned to the baseline value in the sevoflurane group is mainly due to a compensatory adjustment rather than decreased CPP.

Interestingly, in the propofol group, there was no elevation in $\mathrm{rSO}_{2}$ after assuming the Trendelenburg position and creating pneumoperitoneum in this study. A previous study [21] demonstrated that a significantly higher CPP was found in the propofol group compared with the isoflurane and sevoflurane groups in patients with cerebral tumors. Then CBF must be higher in the propofol group and $\mathrm{rSO}_{2}$ has to be as well. It is true only when they have the same pressure-flow curve of cerebral autoregulation and cerebrovascular resistance. Dosedependent cerebral vasodilation of volatile anesthetics results in attenuation of autoregulatory capacity which means that the autoregulatory plateau becomes a positive slope. Also, both the upper and lower thresholds are shifted to the left [22]. In acute intracranial hypertension, upper and lower limits of the autoregulatory plateau were shifted to the left and the autoregulatory plateau narrowed, because the shift of the upper limit was more pronounced than that of the lower limit [23]. Although a recent study [24] reported no change in CBF velocity in response to phenylephrine-induced increases in MAP during anesthesia with 1.5 MAC sevoflurane, a low dose of sevoflurane may cause a small positive slope, whereas propofol may not [25]. We assume that a slight increase of CPP resulted in a greater increase of $\mathrm{CBF}$ induced by the positive pressure-flow curve in the sevoflurane group. In contrast, though CPP was higher in the propofol group, the plateau pressure-flow curve caused CBF to remain unchanged. An explanation for the $\mathrm{rSO}_{2}$ value at Tpost in the propofol group, which was significantly lower than the baseline value, remains elusive. A previous study [13] suggested that propofol might have direct cerebral vasoconstricting activity, which might lead to a decrease in CBF. Intact CBF autoregulation and cerebral vasoconstricting activity of propofol might cause $\mathrm{rSO}_{2}$ to decrease during the pneumoperitoneum in the Trendelenburg position and even after desufflation of the abdomen in the neutral position.

This study has several limitations. First, although NIRS is a continuous, noninvasive monitor used to evaluate the adequacy of regional cerebral oxygenation, this technique measures only regional oxygenation of the frontal cortex [5]. Therefore, changes in $\mathrm{rSO}_{2}$ do not imply cerebral global oxygenation. And NIRS measures oxyhemoglobin in the entire tissue bed, which means that it is unable to distinguish between arterial and venous saturation [26]. Second, we did not measure the velocity of the middle cerebral artery for the CBF autoregulation test which might be a key mechanism in this study. Further studies are needed to determine whether sevoflurane and propofol alter CBF autoregulation during laparoscopic surgery. Third, 
we measured postoperative complications, such as nausea, vomiting, headache, blurred vision, and neurologic deficits that might indicate increased ICP or cerebral hypoperfusion. Although the incidence of complications was significantly higher in the sevoflurane group, which showed conflicting results with $\mathrm{rSO}_{2}$ values, all complications in the sevoflurane group were nausea. However, it is well known that PONV occur more frequently in sevoflurane anesthesia than in propofol anesthesia [27]. It is difficult to determine whether the nausea was a simple PONV or a complication of increased ICP.

In summary, the propofol group showed significantly lower $\mathrm{rSO}_{2}$ values than the sevoflurane group in gynecological laparoscopic surgery not only during pneumoperitoneum in the Trendelenburg position but also after desufflation of the abdomen in the neutral position. Moreover, since cases of cerebral oxygen desaturtaion occurred only in the propofol group $(n=2)$, the possibility of cerebral oxygen desaturation should not be overlooked during propofol anesthesia even after desufflation of the abdomen in the neutral position.

\section{References}

1. Mavrocordatos P, Bissonnette B, Ravussin P. Effects of neck position and head elevation on intracranial pressure in anaesthetized neurosurgical patients: preliminary results. J Neurosurg Anesthesiol 2000; 12: 10-4.

2. Lovell AT, Marshall AC, Elwell CE, Smith M, Goldstone JC. Changes in cerebral blood volume with changes in position in awake and anesthetized subjects. Anesth Analg 2000; 90: 372-6.

3. Halverson A, Buchanan R, Jacobs L, Shayani V, Hunt T, Riedel C, et al. Evaluation of mechanism of increased intracranial pressure with insufflation. Surg Endosc 1998; 12: 266-9.

4. Huettemann E, Terborg C, Sakka SG, Petrat G, Schier F, Reinhart K. Preserved $\mathrm{CO}(2)$ reactivity and increase in middle cerebral arterial blood flow velocity during laparoscopic surgery in children. Anesth Analg 2002; 94: 255-8.

5. Casati A, Spreafico E, Putzu M, Fanelli G. New technology for noninvasive brain monitoring: continuous cerebral oximetry. Minerva Anestesiol 2006; 72: 605-25.

6. Bhatia R, Hampton T, Malde S, Kandala NB, Muammar M, Deasy $\mathrm{N}$, et al. The application of near-infrared oximetry to cerebral monitoring during aneurysm embolization: a comparison with intraprocedural angiography. J Neurosurg Anesthesiol 2007; 19: 97 104.

7. Moritz S, Kasprzak P, Arlt M, Taeger K, Metz C. Accuracy of cerebral monitoring in detecting cerebral ischemia during carotid endarterectomy: a comparison of transcranial Doppler sonography, nearinfrared spectroscopy, stump pressure, and somatosensory evoked potentials. Anesthesiology 2007; 107: 563-9.

8. Ogasawara K, Konno H, Yukawa H, Endo H, Inoue T, Ogawa A. Transcranial regional cerebral oxygen saturation monitoring during carotid endarterectomy as a predictor of postoperative hyperperfusion. Neurosurgery 2003; 53: 309-14.
9. Lee JR, Lee PB, Do SH, Jeon YT, Lee JM, Hwang JY, et al. The effect of gynaecological laparoscopic surgery on cerebral oxygenation. J Int Med Res 2006; 34: 531-6.

10. Park EY, Koo BN, Min KT, Nam SH. The effect of pneumoperitoneum in the steep Trendelenburg position on cerebral oxygenation. Acta Anaesthesiol Scand 2009; 53: 895-9.

11. Harrison GR. The effect of posture on cerebral oxygenation during abdominal surgery. Anaesthesia 2001; 56: 1181-4.

12. Engelhard K, Werner C. Inhalational or intravenous anesthetics for craniotomies? Pro inhalational. Curr Opin Anaesthesiol 2006; 19: 504-8.

13. Van Hemelrijck J, Fitch W, Mattheussen M, Van Aken H, Plets C, Lauwers T. Effect of propofol on cerebral circulation and autoregulation in the baboon. Anesth Analg 1990; 71: 49-54.

14. Mielck F, Stephan H, Weyland A, Sonntag H. Effects of one minimum alveolar anesthetic concentration sevoflurane on cerebral metabolism, blood flow, and CO2 reactivity in cardiac patients. Anesth Analg 1999; 89: 364-9.

15. Vandesteene A, Trempont V, Engelman E, Deloof T, Focroul M, Schoutens A, et al. Effect of propofol on cerebral blood flow and metabolism in man. Anaesthesia 1988; 43: 42-3.

16. Muñoz HR, Núñez GE, de la Fuente JE, Campos MG. The effect of nitrous oxide on jugular bulb oxygen saturation during remifentanil plus target-controlled infusion propofol or sevoflurane in patients with brain tumors. Anesth Analg 2002; 94: 389-92.

17. Kaisti KK, Långsjö JW, Aalto S, Oikonen V, Sipilä H, Teräs M, et al. Effects of sevoflurane, propofol, and adjunct nitrous oxide on regional cerebral blood flow, oxygen consumption, and blood volume in humans. Anesthesiology 2003; 99: 603-13.

18. Kalmar AF, Foubert L, Hendrickx JF, Mottrie A, Absalom A, Mortier EP, et al. Influence of steep Trendelenburg position and $\mathrm{CO}(2)$ pneumoperitoneum on cardiovascular, cerebrovascular, and respiratory homeostasis during robotic prostatectomy. Br J Anaesth 2010; 104: 433-9.

19. Alkire MT. Quantitative EEG correlations with brain glucose metabolic rate during anesthesia in volunteers. Anesthesiology 1998; 89: 323-33.

20. Kirkinen P, Hirvonen E, Kauko M, Purhonen S, Nuutinen L. Intracranial blood flow during laparoscopic hysterectomy. Acta Obstet Gynecol Scand 1995; 74: 71-4.

21. Petersen KD, Landsfeldt U, Cold GE, Petersen CB, Mau S, Hauerberg J, et al. Intracranial pressure and cerebral hemodynamic in patients with cerebral tumors: a randomized prospective study of patients subjected to craniotomy in propofol-fentanyl, isofluranefentanyl, or sevoflurane-fentanyl anesthesia. Anesthesiology 2003; 98: 329-36.

22. Piyush MP, John CD. Cerebral physiology and the effects of anesthetic drugs. In: Miller's Anesthesia. 7th ed. Edited by Miller RD, Eriksson LI, Fleisher LA, Wiener-Kronish JP, Young WL: Philadelphia, Churchill Livingstone. 2009, p 309.

23. Hauerberg J, Xiaodong M, Willumsen L, Pedersen DB, Juhler M. The upper limit of cerebral blood flow autoregulation in acute intracranial hypertension. J Neurosurg Anesthesiol 1998; 10: 10612.

24. Gupta S, Heath K, Matta BF. Effect of incremental doses of sevoflurane on cerebral pressure autoregulation in humans. $\mathrm{Br} \mathrm{J}$ 
Anaesth 1997; 79: 469-72.

25. Strebel S, Lam AM, Matta B, Mayberg TS, Aaslid R, Newell DW. Dynamic and static cerebral autoregulation during isoflurane, desflurane, and propofol anesthesia. Anesthesiology 1995; 83: 6676.

26. Murkin JM, Arango M. Near-infrared spectroscopy as an index of brain and tissue oxygenation. Br J Anaesth 2009; 103: i3-13.

27. Chung JH, Kim YH, Ko YK, Lee SY, Nam YT, Yoon SH. Vomiting after a pediatric adenotonsillectomy: comparison between propofol induced sevoflurane-nitrous oxide maintained anesthesia and TIVA with propofol-remifentanil. Korean J Anesthesiol 2010; 59: 185-9. 